\title{
$\beta$-TrCP1 degradation is a novel action mechanism of PI3K/mTOR inhibitors in triple-negative breast cancer cells
}

\author{
Yong Weon Yi ${ }^{1,2}$, Hyo Jin Kang ${ }^{1}$, Edward Jeong Bae ${ }^{1,3}$, Seunghoon $\mathrm{Oh}^{4}$, Yeon-Sun Seong ${ }^{1,2}$ and Insoo Bae $e^{1,2}$ \\ An F-box protein, $\beta$-TrCP recognizes substrate proteins and destabilizes them through ubiquitin-dependent proteolysis. \\ It regulates the stability of diverse proteins and functions as either a tumor suppressor or an oncogene. Although the regulation \\ by $\beta$-TrCP has been widely studied, the regulation of $\beta$-TrCP itself is not well understood yet. In this study, we found that \\ the level of $\beta$-TrCP1 is downregulated by various protein kinase inhibitors in triple-negative breast cancer (TNBC) cells. \\ A PI3K/mTOR inhibitor PI-103 reduced the level of $\beta$-TrCP1 in a wide range of TNBC cells in a proteasome-dependent manner. \\ Concomitantly, the levels of c-Myc and cyclin $\mathrm{E}$ were also downregulated by $\mathrm{PI}-103$. $\mathrm{PI}-103$ reduced the phosphorylation of \\ $\beta$-TrCP1 prior to its degradation. In addition, knockdown of $\beta$-TrCP1 inhibited the proliferation of TNBC cells. We further \\ identified that pharmacological inhibition of mTORC2 was sufficient to reduce the $\beta$-TrCP1 and c-Myc levels. These results \\ suggest that mTORC2 regulates the stability of $\beta$-TrCP1 in TNBC cells and targeting $\beta$-TrCP1 is a potential approach to treat \\ human TNBC.
}

Experimental \& Molecular Medicine (2015) 47, e143; doi:10.1038/emm.2014.127; published online 27 February 2015

\section{INTRODUCTION}

Triple-negative breast cancers (TNBCs), which were first introduced in the medical literature in 2005 , are a heterogeneous group of tumors that are immunohistologically defined as the lack of estrogen receptor (ER) and progesterone receptor (PR) expression, as well as human epidermal growth factor receptor 2 expression/amplification. ${ }^{1}$ Despite marked increase of studies on TNBCs during the past decade, our knowledge of how TNBCs can be treated is still limited. ${ }^{2-4}$ Approximately 15 to $20 \%$ of all breast cancers are diagnosed as TNBCs. ${ }^{4}$ A systemic review demonstrated the highest incidence of TNBCs in women of African ancestry (26.99\%) followed by Hispanic (17.5\%), Asian (12.19\%), Caucasian (11.73\%) and other women $(8.42 \%) .{ }^{5} \mathrm{~A}$ recent meta-analysis of large data sets revealed that TNBCs are classified in at least six distinct molecular subtypes that include two basal-like, an immunomodulatory, a mesenchymal, a mesenchymal stem-like and a luminal androgen receptor subtype. ${ }^{6}$ However, no successful therapeutic target is currently available to treat TNBC patients. $^{2-4}$
Beta-transducin repeat containing proteins $(\beta$-TrCPs) are members of the F-box/WD repeat-containing protein (FBXW) subfamily of F-box protein families. ${ }^{7-9}$ As an F-box protein, the $\beta$-TrCP is the substrate-recognition subunit of SKP1-cullin 1-F-box protein, E3 ligase complexes and well conserved across species. ${ }^{8,9}$ In humans, $\beta$-TrCP exists as two homologues, $\beta$-TrCP1 (also known as FBXW1) and $\beta$-TrCP2 (also known as FBXW11), which are encoded by two distinct genes but share extensive amino acid sequence homology. The differences between these two proteins still remain elusive. ${ }^{8,9}$ The function of $\beta$-TrCPs in tumorigenesis is either oncogenic or tumor-suppressive in a tissue-specific or cellular contextdependent manner homology. ${ }^{8,9}$ Although it has been widely studied that $\beta$-TrCP recognizes diverse proteins and regulates their stability, the regulation of $\beta$-TrCP itself is not yet understood.

Here, we demonstrated that the expression of $\beta$-TrCP1 protein is regulated by mTORC2 and targeting $\beta-\operatorname{TrCP} 1$ is a potential therapeutic approach to treat TNBC cells.

\footnotetext{
${ }^{1}$ Department of Oncology, Lombardi Comprehensive Cancer Center, Georgetown University Medical Center, Washington, DC, USA; ${ }^{2}$ Department of Nanobiomedical Science \& BK21 PLUS Research Center for Regenerative Medicine, Dankook University, Cheonan, Korea; ${ }^{3}$ Department of Nursing and Health Studies, Georgetown University, Washington, DC, USA and ${ }^{4}$ Department of Physiology, College of Medicine, Dankook University, Cheonan, Korea Correspondence: Professor YS Seong, Department of Nanobiomedical Science \& BK21 PLUS Research Center for Regenerative Medicine, Dankook University, 119 Dandae-Ro, Dongnam-Gu, Cheonan, Chungnam 330-714, Korea.
}

E-mail: seongys@dankook.ac.kr

Received 21 November 2014; revised 4 December 2014; accepted 10 December 2014 


\section{MATERIALS AND METHODS}

Cell culture and reagents

Cell culture reagents were purchased from Invitrogen (Carlsbad, CA, USA), Lonza (Basel, Switzerland), or Cellgro (Manassas, VA, USA), All cells, except for SUM149PT, were obtained from the Tissue Culture Shared Resource of Georgetown University Medical Center (Washington, DC, USA) and maintained in the Dulbecco's Modified Eagle Medium (DMEM; Lonza) containing 10\% heat inactivated fetal bovine serum (FBS; HyClone, Logan, UT, USA or Omega Scientific,
Tarzana, CA, USA) and 100 units $\mathrm{ml}^{-1}$ penicillin/streptomycin (Lonza). SUM149PT was maintained according to manufacturer's recommendation (Asterand, Detroit, MI, USA). The viability of cultured cells was monitored by the trypan blue dye-exclusion method using the Luna Automated Cell Counter (Logos Biosystems, Gyeonggi-do, Korea). Protein kinase inhibitors were purchased from the following sources: CHIR-99021, GDC-0941, GSK1059615, IC-87114, MK-2206, PI-103, PIK-75, PIK-90, TG100-115, TGX221 and WYE-354 from Selleck Chemicals (Houston, TX, USA); BEZ235 a

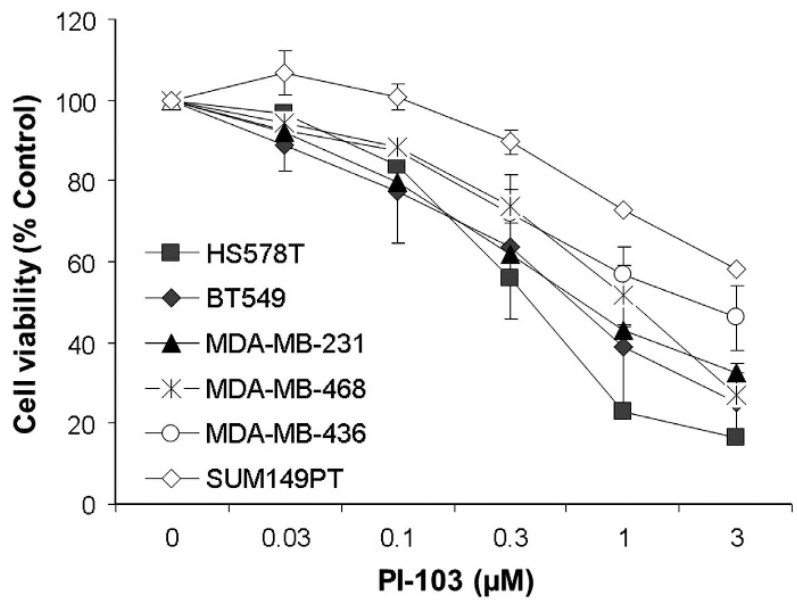

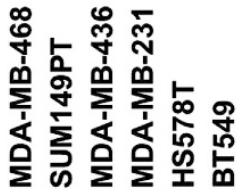

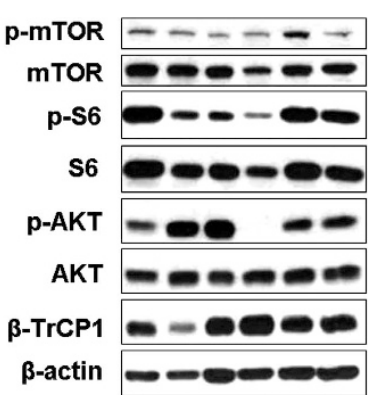

b

\begin{tabular}{|c|c|c|c|c|c|}
\hline Cell line & Subtype & $\mathrm{EC}_{50}(\mu \mathrm{M})$ for $\mathrm{Pl}-103$ & p-AKT/AKT & $\beta$-TrCP $1 / \beta$-actin & p-AKT/ß-TrCP1 \\
\hline HS578T & MSL & $0.48 \pm 0.03$ & 1.06 & 0.85 & 1.25 \\
\hline BT549 & M & $0.49 \pm 0.29$ & 1.14 & 0.87 & 1.31 \\
\hline MDA-MB-231 & MSL & $0.79 \pm 0.04$ & 0.00 & 1.40 & 0.00 \\
\hline MDA-MB-468 & BL1 & $1.01 \pm 0.11$ & 1.00 & 1.00 & 1.00 \\
\hline MDA-MB-436 & MSL & $2.19 \pm 0.94$ & 2.70 & 0.93 & 2.90 \\
\hline SUM149PT & BL2 & $3.47 \pm 0.12$ & 1.90 & 0.48 & 3.96 \\
\hline
\end{tabular}

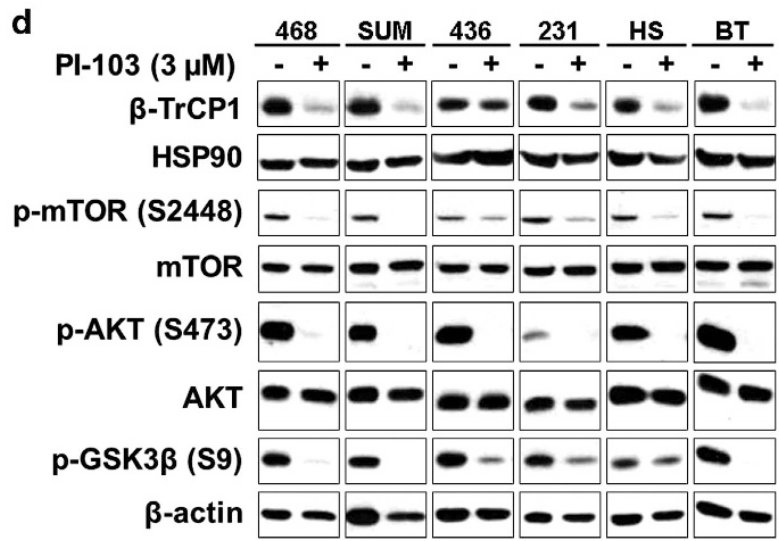

Figure $1 \mathrm{PI}-103$ downregulates the level of $\beta$-TrCP1 protein in TNBC cells. (a) PI-103 reduced the viable TNBC cells in a dose-dependent manner. Cells were treated with increasing amounts of PI-103 up to $72 \mathrm{~h}$ and the viable cells were measured by MTT assay. Data from two independent experiments performed in triplicate are shown as mean \pm s.e.m. (b) $\mathrm{EC}_{50}$ values of PI-103 and the relative protein expression in TNBC cells. $E_{50}$ values were obtained from data in a and the relative protein expression was obtained by densitometric analysis of data in c. (c) The levels of protein expression in TNBC cells. Cell lysates from exponentially growing cells were subjected to western blot analysis with indicated antibodies. $\beta$-actin was used as a loading control. (d) PI-103 reduced the level of $\beta$-TrCP1 protein in TNBC cells. Cells were treated with $3 \mu \mathrm{m}$ of $\mathrm{PI}-103$ for $24 \mathrm{~h}$ and subjected to western blot analysis with indicated antibodies. HSP90 or $\beta$-actin was used as a loading control. 
and ZSTK474 from LC Labs (Woburn, MA, USA). Bafilomycin A1, MG132 and rapamycin were purchased from Sigma (St Louis, MO, USA). Stock solutions of compounds, except for BEZ235, were made in dimethyl sulfoxide and stored at $-20^{\circ} \mathrm{C}$ in small aliquots. BEZ235 was dissolved in dimethylformamide.

\section{MTT (3-(4,5-Dimethylthiazol-2-yl)-2,5-diphenyltetrazolium} bromide) cell viability assays

Cell viability was determined at $\sim 72 \mathrm{~h}$ after treatment of compounds by MTT assay as described previously. ${ }^{10,11}$ The $\mathrm{EC}_{50}$ values were calculated by CompuSyn software V1.0 (ComboSyn, Paramus, NJ, USA).

\section{Western blots and antibodies}

Western blot analyses were performed as described previously. ${ }^{10}$ Antibodies used in this study were as follows: phospho-AKT (Ser473; \#9271), AKT (\#9272), phospho-GSK3 $\beta$ (S9; \#9323), LC3B (\#3868), phospho-mTOR (S2448; \#2971), mTOR (\#4517), p-S6 (S235/S236; \#4856), S6 (\#2217) and $\beta$-TrCP (\#4394) from Cell Signaling (Danvers, MA, USA); $\beta$-TrCP (sc-390629), HSP90 (sc-7947), c-Myc (sc-764) from Santa Cruz (Santa Cruz, CA, USA); cyclin E (51-1459GR) from BD Biosciences (San Jose, CA, USA) and $\beta$-actin and horseradish peroxidase-conjugated secondary antibodies from Sigma. Densitometric analysis was performed by ImageJ $(\mathrm{NIH}$, Bethesda, MD, USA). ${ }^{12}$

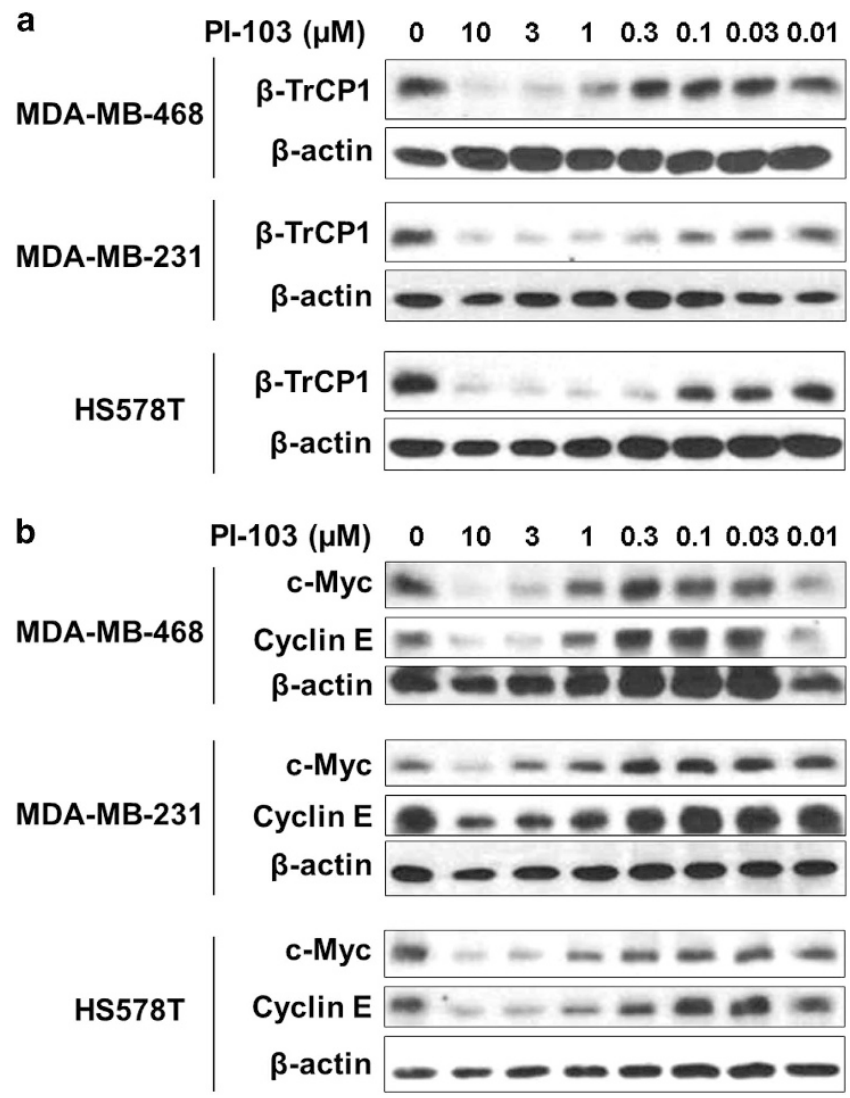

Figure $2 \mathrm{PI}-103$ downregulates the levels of $\beta-\operatorname{TrCP} 1, \mathrm{c}-\mathrm{Myc}$ and cyclin $E$ proteins in TNBC cells. (a, b) Cells were treated with increasing concentrations of $\mathrm{Pl}-103$ for $24 \mathrm{~h}$ and the cell lysates were subjected to western blot analysis with indicated antibodies. $\beta$-actin was used as a loading control.

\section{Immunoprecipitation}

Immunoprecipitation was performed as described previously ${ }^{13}$ with phospho-(Ser/Thr) Phe (\#9631) antibody. Then, immune complexes were dissolved on SDS-poly acrylamide gel electrophoresis and western blot analysis was performed with mouse $\beta$-TrCP antibody (sc-390629) from Santa Cruz.

\section{Transfection of small interference RNA and cell proliferation} assay

Transfection of small interference RNA (siRNA) was performed with Lipofectamine 2000 (Invitrogen) as described previously. ${ }^{14}$ In brief, HS578T $\left(0.4 \times 10^{5}\right.$ cells per well $)$ or MDA-MB-231 $\left(1.0 \times 10^{5}\right.$ cells per well) cells in six-well plates were transfected with 100 pmoles of siRNA and $2.5 \mu \mathrm{l}$ of Lipofectamine 2000 in serum-free DMEM. After $4 \mathrm{~h}$ incubation, cells were supplemented with equal volume of DMEM containing $20 \% \mathrm{FBS}$ and 200 units $\mathrm{ml}^{-1}$ penicillin/streptomycin to maintain final 10\% FBS and further incubated for 3 days. After 3-day incubation, cells were further supplemented with equal volume of

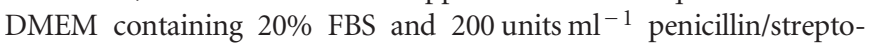
mycin and incubated up to two more days. The cells were trypsinized at indicated days and the number of viable cells was determined by counting cells which were stained by acridine orange/propidium iodide with the Luna-FL Dual Fluorescence Cell Counter (Logos Biosystems). The siRNAs were purchased from Bioneer (Seoul, Korea) with following sequences: control-siRNA 5'-GAC GAG CGG CAC GUG CAC AUU-3'; $\beta$-TrCP1-siRNA \#3, 5'-CUC AGA GAG AGA AGA CUG U(dTdT)-3'; $\beta$-TrCP1-siRNA \#4, 5'-GUG AUG UGU AGU CAG UGU A(dTdT)-3'; $\beta$-TrCP2-siRNA \#3, 5'-GAA UUC UGA CUU GUU GUA U(dTdT)- $3^{\prime}$ and $\beta$-TrCP2-siRNA \#9, 5'-CAG ACA ACC UUU GAA UUG U(dTdT)-3'.

\section{RESULTS}

A PI3K/mTOR inhibitor PI-103 reduces the viable cells of TNBC cell lines

During our previous study, ${ }^{10}$ we noticed that a PI3K/mTOR inhibitor PI- $103^{15}$ reduced the cell viability of TNBC cells in a dose-dependent manner. As TNBC is a heterogeneous disease which can be further subgrouped into six subtypes, ${ }^{4}$ we further tested the effect of PI-103 with expanded TNBC cell lines by MTT assay. As shown in Figure 1a, PI-103 significantly reduced the number of viable cells in a dose-dependent manner in all of the cell lines tested. There is no significant correlation between the $\mathrm{EC}_{50}$ values for PI-103 and the subtypes of these cell lines (Figure 1b). To further compare the level of proteins in the PI3K/mTOR pathway in these cells, we performed western blot analysis (Figure 1c). All these cells expressed detectable levels of AKT downstream proteins such as phospho-mTOR (Y2448) and p-S6 (S235/S236). As reported previously, ${ }^{16}$ BRCA1defective cells exhibited higher level of phospho-AKT (S473) than other TNBC cells. On the contrary, the expression of phospho-AKT (S473) was barely detectable in MDA-MB-231 cells. Interestingly, significant level of $\beta$-TrCP1 protein was detected in all these cells. There is no significant correlation between the $\mathrm{EC}_{50}$ values of PI-103 and the expression levels of these proteins, whereas high ratio of phospho-AKT to $\beta$-TrCP1 correlated with high $\mathrm{EC}_{50}$ values for PI-103 (Figure 1b).

To determine the effect of PI-103 on the level of these proteins, we performed western blot analysis with cell lysates 
a

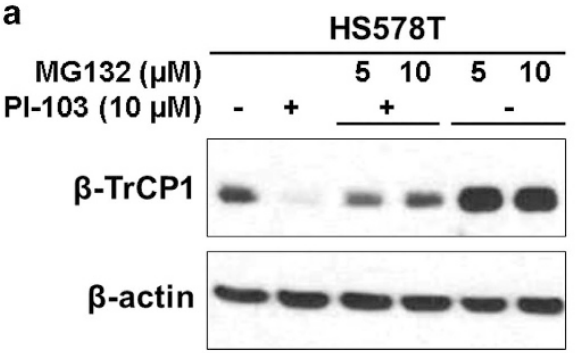

MDA-MB-231

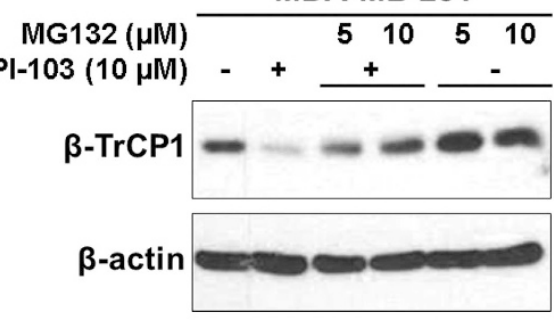

b

MDA-MB-231

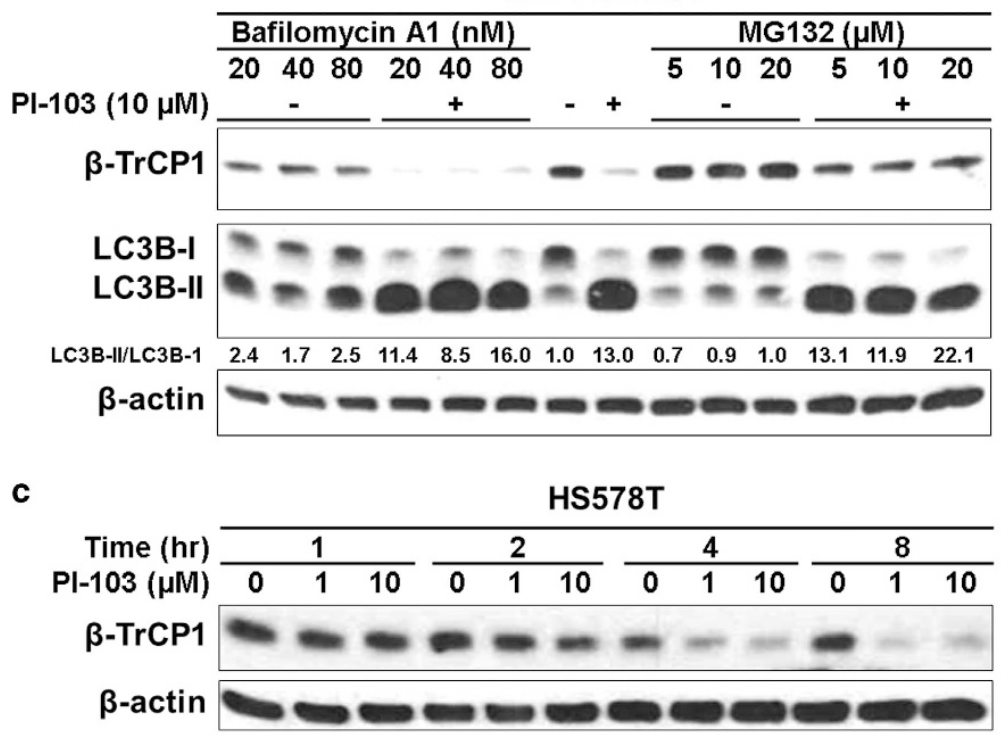

MDA-MB-231

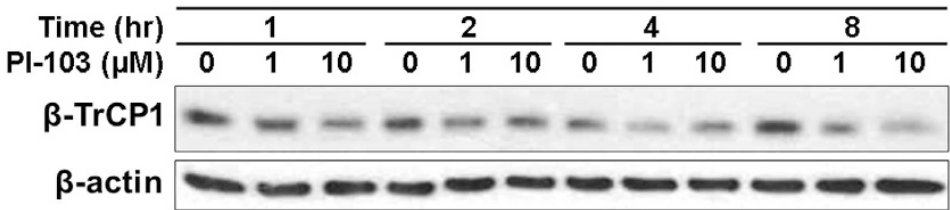

Figure $3 \mathrm{PI}-103$ downregulates the level of $\beta$-TrCP1 protein via proteasome-dependent manner. (a) Cells were treated with $10 \mu \mathrm{M}$ of PI-103 for $20 \mathrm{~h}$ and further incubated for $4 \mathrm{~h}$ in the presence of different concentrations of MG-132. (b) Cells were treated with $10 \mu \mathrm{M}$ of $\mathrm{PI}-103$ for $20 \mathrm{~h}$ and further incubated for $4 \mathrm{~h}$ in the presence of different concentrations of bafilomycin A1 or MG-132. (c) Cells were treated with $\mathrm{PI}-103$ for indicated time. (a-c) Western blot analysis was performed with indicated antibodies. $\beta$-actin was used as a loading control.

from cells treated with $3 \mu \mathrm{M}$ of PI-103 for $24 \mathrm{~h}$ (Figure 1d). As expected, PI-103 reduced the phosphorylation level of AKT substrates including mTOR $(\mathrm{S} 2448)^{17}$ and GSK3 $\beta(\mathrm{S} 9)^{18}$ in all cell lines test. PI-103 also reduced the level of mTORC2 substrate, phospho-AKT (S473). ${ }^{19}$ Unexpectedly, the level of $\beta$-TrCP1 was also reduced by PI-103 in these cells (Figure 1d).

$\mathrm{PI}-103$ reduces the level of $\beta-\operatorname{TrCP}, \mathrm{c}-\mathrm{Myc}$ and cyclin $\mathrm{E}$ in TNBC cells

The effect of PI-103 on the level of $\beta$-TrCP1 was further determined by western blot analyses. Three TNBC cell lines were treated with increasing concentrations of PI-103 for $24 \mathrm{~h}$ and western blot analyses were performed. Consistently, the level of $\beta-\mathrm{TrCP} 1$ was reduced by PI-103 in a dose-dependent manner in all these cells (Figure 2a). It has been reported that $\beta$-TrCP stabilizes c-Myc through antagonizing FBW7-mediated turnover. ${ }^{20}$ It has been also demonstrated that activation of Ras/PI3K/ERK pathway induces c-Myc stabilization in melanoma cells, ${ }^{21}$ and inhibition of PI3K/AKT pathway by LY294002 in melanoma cells, ${ }^{21}$ or by PI-103 in Burkitt's lymphoma cells, ${ }^{22}$ and reduces c-Myc expression. Consistently, the levels of c-Myc and its downstream target, cyclin E, were also reduced by PI-103 in a dose-dependent manner (Figure 2b).

To determine whether the reduction of $\beta-\operatorname{TrCP} 1$ is dependent on proteasome-mediated degradation, western blot analysis was conducted as follows: HS578T and MDAMB-231 cells were treated with PI-103 for $24 \mathrm{~h}$. To inhibit 
proteasome-dependent proteolysis, MG132 was added to the cells $4 \mathrm{~h}$ before harvest. Western blot analysis revealed that PI-103-mediated reduction of $\beta$-TrCP1 was reversed by MG132 in these cells (Figure 3a). In addition, MG132 treatment increased the basal level of $\beta$-TrCP1 in the absence of PI-103 (Figure 3a).

Although it has been reported that PI-103 induces autophagy in glioma cells, ${ }^{17}$ we further accessed the effect of bafilomycin A1, an inhibitor of autophagic vacuole maturation ${ }^{23}$ on the degradation of $\beta$-TrCP1 by PI-103. MDA-MB-231 cells were treated with PI-103 for $24 \mathrm{~h}$ and either bafilomycin A1 or

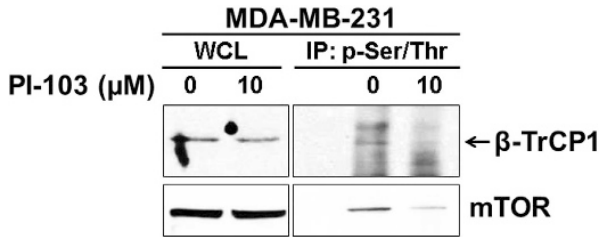

Figure $4 \mathrm{PI}-103$ reduces the phosphorylation of $\beta$-TrCP1. MDAMB-231 cells were treated with $\mathrm{Pl}-103$ for $2 \mathrm{~h}$ and immunoprecipitation of phospho-proteins was performed as described in material and methods. Western blot analysis was performed with indicated antibodies.
MG132 was treated for $4 \mathrm{~h}$ before harvest. As expected, bafilomycin A1 increased the accumulation of LC3B-II, a marker of autophagy, in the absence of PI-103 (Figure 3b). However, bafilomycin A1 did not affect the PI-103-mediated degradation of $\beta$-TrCP1. On the contrary, MG132 reversed the effect of PI-103 on the level of $\beta$-TrCP1 (Figure 3b, lanes 8 and 12-14) without affecting the accumulation of LC3B-II in the absence of PI-103 (Figure 3b, lanes 7 and 9-11). In these conditions, the level of $\beta$-TrCP1 was increased by MG132 even in the absence of PI-103. These implicate the basal level of $\beta$-TrCP1 was regulated by MG132 in these cells. All these results suggest that PI-103 reduced the level of $\beta$-TrCP1 by a proteasome-mediated degradation. The degradation of $\beta$-TrCP1 was observed as early as $4 \mathrm{~h}$ after PI-103 treatment (Figure 3c). Although we cannot completely exclude the possibility of mRNA reduction by PI-103 treatment, rapid reduction of the level of $\beta$-TrCP1 in the time-course treatment of $\beta$-TrCP1 (Figure $3 \mathrm{c}$ ) suggests that proteasomal degradation is a major mechanism of $\beta$-TrCP1 reduction by PI-103.

\section{PI-103 reduces the phosphorylation of $\beta-\operatorname{TrCP1}$}

The $\beta$-TrCP protein has several potential phosphorylation sites (data not shown). To determine whether $\beta$-TrCP1 is
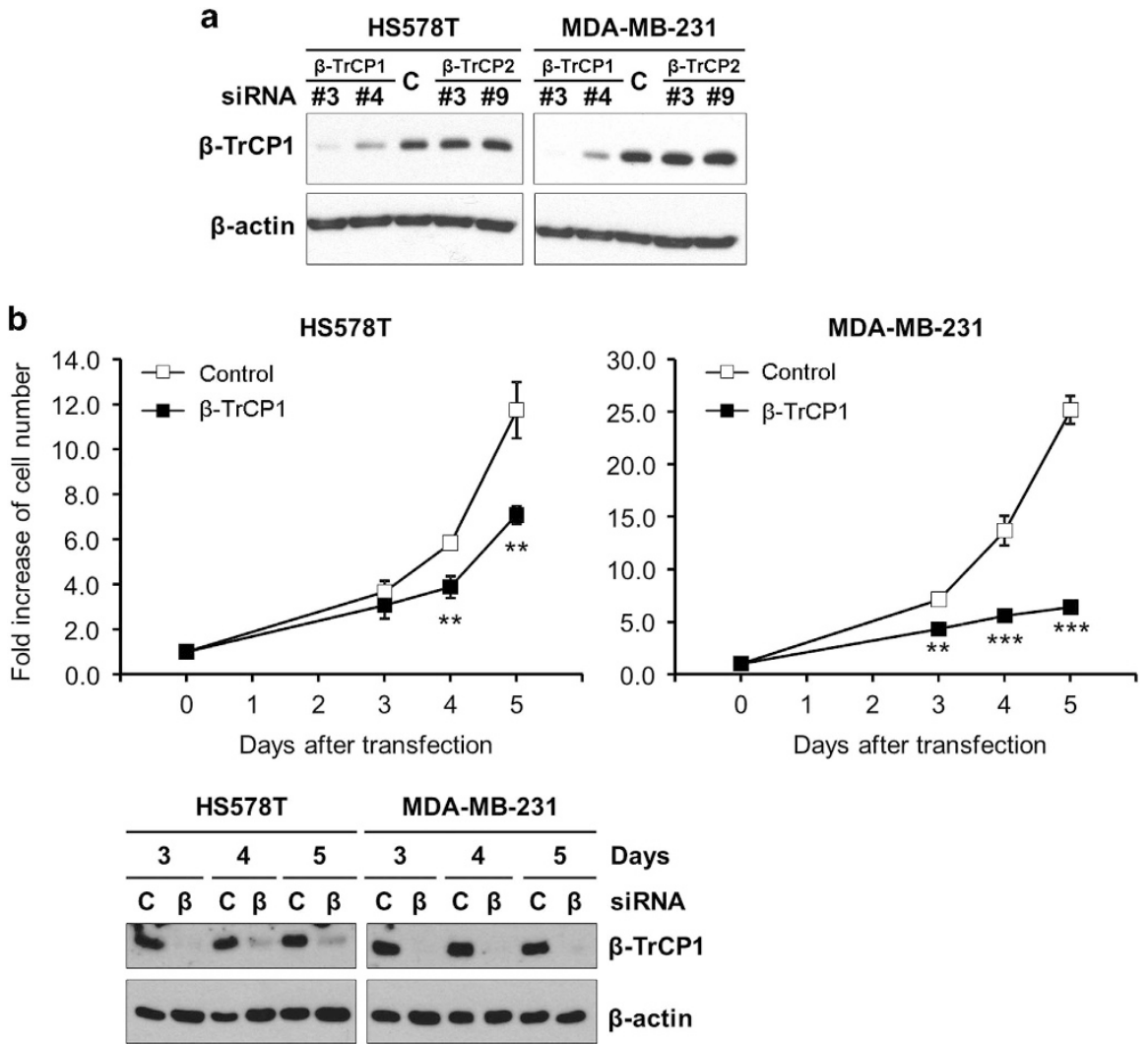

Figure 5 Knockdown of $\beta$-TrCP1 inhibits the proliferation of TNBC cells. (a) HS578T and MDA-MB-231 cells were transfected with siRNAs as indicated for 3 days and western blot analysis was performed with indicated antibodies. $\beta$-actin was used as a loading control. (b) HS578T and MDA-MB-231 cells were transfected with $\beta$-TrCP1-siRNA \#3 as described in Materials and methods and the number of viable cells was determined by acridine orange/propidium iodide staining. Data from two independent experiments performed in triplicate are shown as mean \pm s.e.m. ${ }^{* *} P<0.01$ and $* * * P<0.001$. Western blot analysis of transfected cells was performed with indicated antibodies. $\beta$-actin was used as a loading control. 

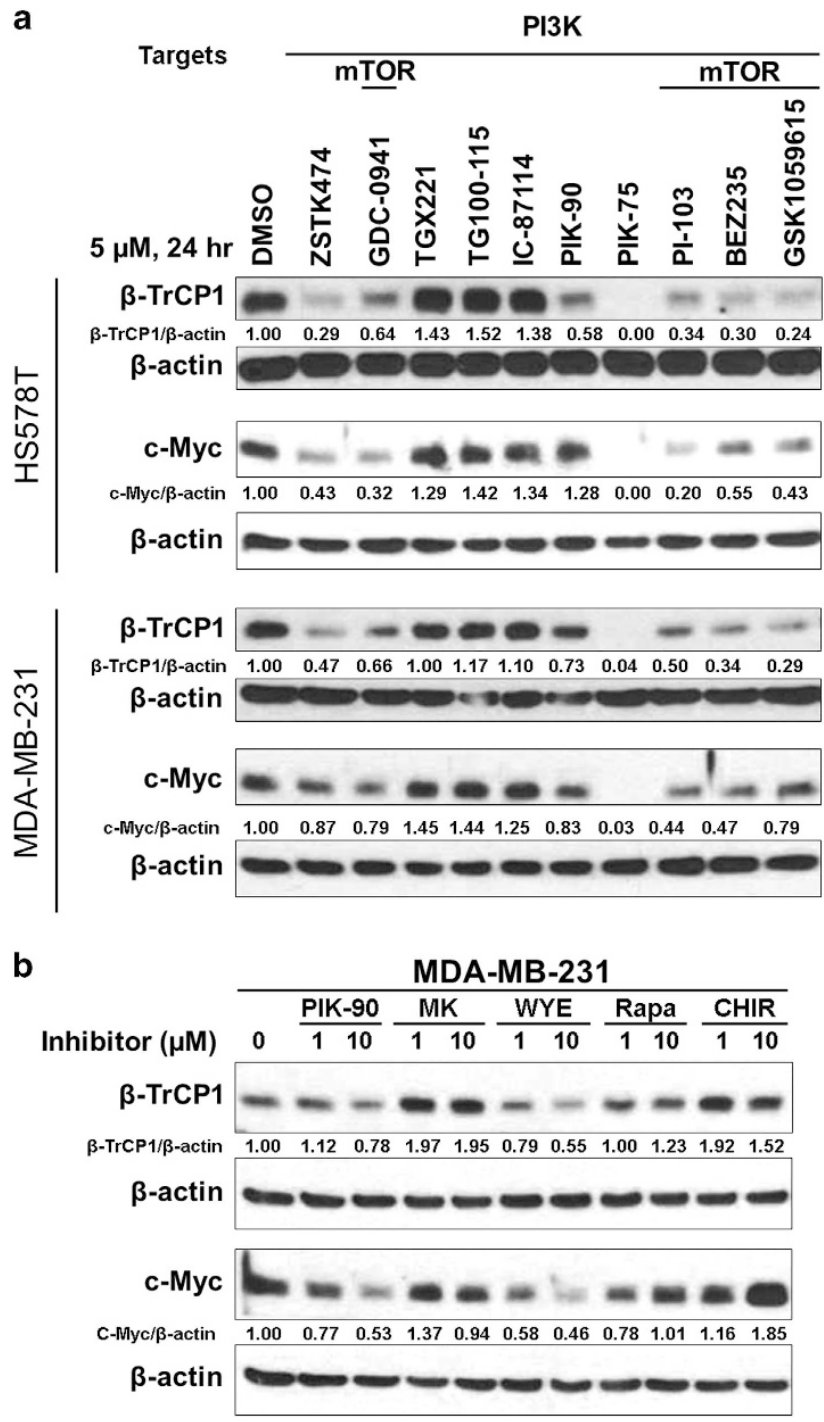

Figure $6 \mathrm{PI} 3 \mathrm{~K} / \mathrm{mTOR}$ inhibitors downregulate the levels of $\beta$-TrCP1 and C-Myc proteins in TNBC cells. (a) Cells were treated with $5 \mu \mathrm{m}$ of compounds for $24 \mathrm{~h}$ and the protein expression was determined by western blot analysis with indicated antibodies. (b) Cells were treated with 1 or $10 \mu \mathrm{m}$ of compounds for $24 \mathrm{~h}$ and the protein expression was determined by western blot analysis with indicated antibodies. (a, b) $\beta$-actin was used as a loading control.

phosphorylated or not, we performed western blot analysis after immunoprecipitation of phospho proteins. To avoid $\beta$-TrCP1 degradation, MDA-MB-231 cells were treated with $10 \mu \mathrm{M}$ of PI-103 for $2 \mathrm{~h}$ and phospho-proteins were immuneprecipitated by phospho-Ser/Thr Phe antibody. Then the immune complexes were analyzed by western blot with $\beta$-TrCP1 antibody. As shown in Figure $4, \beta$-TrCP1 was phosphorylated in MDA-MB-231 cells and brief treatment of PI-103 reduced this phosphorylation. As a control, the level of mTOR protein was also determined. As expected the phosphomTOR (S2448) was reduced by PI-103 treatment without affecting the level of mTOR.
Knockdown of $\beta-\operatorname{TrCP} 1$ reduces the proliferation of TNBC cells

As PI-103 reduced the viable cell numbers and the level of $\beta$-TrCP1 in a broad range of TNBC cells, we questioned whether $\beta$-TrCP1 has a role in the proliferation of TNBC cells. To address this question, we performed knockdown of $\beta$-TrCP1 by siRNA and determined its effect on the proliferation of TNBC cells. HS578T and MDA-MB-231 cells were transfected with specific siRNAs for $\beta$-TrCP1 and for $\beta$-TrCP2 as a control and western blot analysis was performed. As shown in Figure 5a, $\beta$-TrCP1-siRNAs reduced the level of $\beta$-TrCP1.

Next, we determined the number of viable cells at various time points after $\beta$-TrCP1 knockdown in HS578T and MDA-MB-231 cells. Interestingly, knockdown of $\beta$-TrCP1 was enough to reduce the proliferation of these cells (Figure $5 b$ ). The anti-proliferative effect was evident at 3 or 4 days after $\beta$-TrCP1 knockdown and sustained up to 5 days. Western blot analysis revealed that the level of $\beta$ - TrCP1 was slightly reversed over the time in HS578T cells, whereas no significant restoration of $\beta$-TrCP1 was observed in MDA-MB-231 cells. Consistent with these, the anti-proliferative effect of $\beta$-TrCP1 knockdown was more profound in MDA-MB-231 cells.

Pharmacological inhibition of mTORC2 reduces the level of $\beta$-TrCP1 protein

To identify the kinase responsible for the phosphorylation of $\beta$-TrCP1, HS578T and MDA-MB-231 cells were treated with various PI3K/mTOR inhibitors for $24 \mathrm{~h}$. As shown in Figure 6a, most of the PI3K inhibitors reduced the level of $\beta$-TrCP1 in these cells. Notably, PI3K inhibitors, which are known to inhibit preferentially $\mathrm{PI} 3 \mathrm{~K} \alpha$, markedly reduced the $\beta-\mathrm{TrCP} 1$ protein, whereas PI3K inhibitors (TGX221, TG100-115 and IC-87114) specific to other isoforms $(\beta, \delta \text { and } \gamma)^{15,24}$ exhibited little or no effect on the level of $\beta$-TrCP1 protein. More interestingly, all of the PI3K/mTOR dual inhibitors, such as GDC-0941, ${ }^{25}$ PI-103, ${ }^{15}$ BEZ235 ${ }^{26}$ and GSK1059615 ${ }^{27}$ invariantly reduced the level of $\beta-\operatorname{TrCP} 1$ protein (Figure 6a). Again, the level of c-Myc was concomitantly reduced by inhibitors which reduced the level of $\beta-\operatorname{TrCP} 1$.

To further dissect the pathway to $\beta$-TrCP1 degradation, MDA-MB-231 cells were treated with different concentrations of more specific inhibitors. As shown in Figure 6b, a PI3K inhibitor PIK-90 and mTOR-kinase inhibitor WYE-354 28 reduced the levels of $\beta$-TrCP1 and $\mathrm{c}-\mathrm{Myc}$ in a dosedependent manner. On the contrary, the level of $\beta-\mathrm{TrCP} 1$ protein was rather induced by other inhibitors including an allosteric AKT inhibitor MK-2206, ${ }^{29}$ an allosteric mTORC1 inhibitor rapamycin, ${ }^{30}$ and a GSK3 $\alpha / \beta$ inhibitor CHIR-99021. ${ }^{31}$ As an mTOR kinase inhibitor, WYE-354 inhibits both mTORC1 and mTORC2 $2{ }^{28}$ whereas rapamycin more specifically inhibits mTORC1. ${ }^{30}$ Taken together, we speculated that mTORC2 is a potential kinase that stabilizes the $\beta$-TrCP1 protein in TNBC cells. 


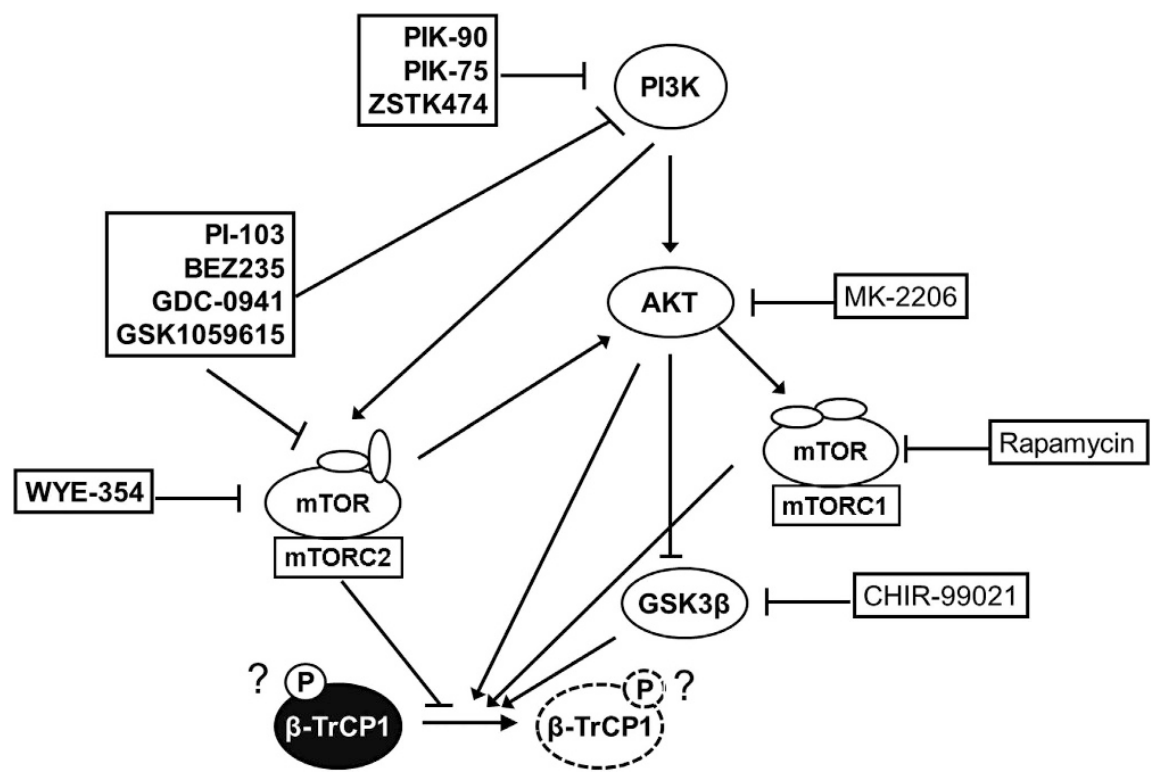

Figure 7 Schematic diagram for proposed regulation of $\beta$-TrCP1 by upstream kinases.

\section{DISCUSSION}

In the present study, we identified $\beta$-TrCP1 as a potential target to treat the TNBC cells. Inhibition of PI3K/mTOR by PI-103 reduced the level of $\beta$-TrCP1 in diverse TNBC cell lines in a proteasome-dependent manner. siRNA-based depletion of $\beta$-TrCP1 profoundly reduced the proliferation of TNBC cell lines, HS578T and MDA-MB-231. Pharmacological inhibition of mTORC2 but not mTORC1 was sufficient to reduce the level of $\beta$-TrCP1 and c-Myc in TNBC cells.

Treatment of a series of specific kinase inhibitors revealed that mTORC2 is a plausible regulator of $\beta$ - TrCP1 stability in TNBC cells. Treatment of PI-103 reduced the level of phospho$\beta$-TrCP1. PI3K/mTOR inhibitors reduced the level of $\beta$-TrCP1, whereas MK-2206 (an allosteric AKT inhibitor) did not reduce the $\beta$-TrCP1 protein in TNBC cells. Because the inhibition of $\mathrm{PI} 3 \mathrm{~K}$ reduces the activity of $\mathrm{AKT}$ that activates mTORC1 activity, these results are somewhat complicated. However, a recent report suggested that the activity of mTORC2 can be directly regulated by $\mathrm{PI} 3 \mathrm{~K}$ in a TSC-independent manner. ${ }^{32,33}$ In addition, WYE-354, an mTOR-kinase inhibitor, reduced the level of $\beta$-TrCP1. On the contrary, rapamycin, an mTORC1 inhibitor, did not affect the $\beta$-TrCP1 level. All these results suggest that the level of $\beta$-TrCP1 protein is regulated by mTORC2 in TNBC cells (Figure 7). Future studies with specific siRNAs for components of PI3K/mTORC2 pathway will further delineate the signaling pathway that is important to regulate $\beta$-TrCP1 stability.

The stability of F-box itself is also regulated by posttranslational regulation. As an example, S-phase kinaseassociated protein 2, another oncogenic F-box protein, has been reported to be phosphorylated and stabilized by AKT1 in human cancers. ${ }^{34}$ However, the regulation of $\beta$-TrCP1 stability through post-translational modification has not been attributed yet. Our present data, which demonstrates that PI-103 reduced the level of phospho- $\beta$-TrCP1, suggest that the stability of $\beta$-TrCP1 might be also regulated by protein modification. Recently, S-phase kinase-associated protein 2 has been identified as an E3 ligase that is responsible for degradation of $\beta$-TrCP. ${ }^{35}$ In fact, $\beta$-TrCP itself is an E3 ligase for degradation of Emi1,36,37 an inhibitor of the APC/C E3 ligase which mediates S-phase kinase-associated protein 2 degradation. ${ }^{38,39}$ More recently, SIRT1 has been identified as a negative regulator of $\beta$-TrCP through protein degradation. ${ }^{40}$

Although reported to function as a tissue-specific tumor suppressor, multiple studies have supported that $\beta$-TrCP has roles as an oncogene and promotes tumorigenesis when overexpressed and elevated levels of $\beta$ - TrCP has been reported various human cancers including hepatoblastoma, melanoma, colorectal, pancreatic, prostate, breast and gastric cancers. ${ }^{8,9}$ In fact, potential tumor-suppressor function is a common property of many $\beta$-TrCP substrates such as inhibitor of nuclear factor- $\kappa \mathrm{B}(\mathrm{I} \kappa \mathrm{B})$, programmed cell-death protein 4 (PDCD4), DEP domain-containing mTOR-interacting protein (DEPTOR), RE1-silencing transcription factor (REST) and metastasis suppressor 1 (MTSS1). ${ }^{8,9,41,42}$ Interestingly, phosphorylation of DEPTOR, a negative regulator of $\mathrm{mTORC1/2}$, generates phosphodegron that binds $\beta$-TrCP and leads to degradation of DEPTOR. ${ }^{43-45}$ In addition, depletion of $\beta$-TrCP by shRNA induced accumulation of DEPTOR, reduced mTOR and S6 kinase activity and activated autophagy to reduce cell growth. ${ }^{44,45}$ These results suggest that $\beta$-TrCP1 is an important candidate of druggable target protein to treat cancers via modulating cell proliferation and/or survival.

\section{CONFLICT OF INTEREST}

The authors declare no conflict of interest. 


\section{ACKNOWLEDGEMENTS}

This work was supported by the Susan G. Komen for the Cure (FAS0703858); and by the Lombardi Comprehensive Cancer Center, Georgetown University Medical Center (P30-CA051008) awarded to late I.B.

1 Brenton JD, Carey LA, Ahmed AA, Caldas C. Molecular classification and molecular forecasting of breast cancer: ready for clinical application? J Clin Oncol 2005; 23: 7350-7360.

2 Clark O, Botrel TE, Paladini L, Ferreira MB. Targeted therapy in triplenegative metastatic breast cancer: a systematic review and meta-analysis. Core Evid 2014; 9: 1-11

3 Herold $\mathrm{Cl}$, Anders CK. New targets for triple-negative breast cancer. Oncology 2013; 27: 846-854.

4 Lehmann BD, Pietenpol JA. Identification and use of biomarkers in treatment strategies for triple-negative breast cancer subtypes. J Pathol 2014; 232: 142-150.

5 Limbada R, Slater A, Jain A. PB.53: are ethnic minorities more likely to develop triple-negative breast cancer? A systematic review. Breast Cancer Res 2013; 15(Suppl 1): P53.

6 Lehmann BD, Bauer JA, Chen X, Sanders ME, Chakravarthy AB, Shyr Y et al. Identification of human triple-negative breast cancer subtypes and preclinical models for selection of targeted therapies. J Clin Invest 2011; 121: 2750-2767.

7 Kipreos ET, Pagano M. The F-box protein family. Genome Biol 2000; 1: Review S3002.

8 Wang Z, Liu P, Inuzuka H, Wei W. Roles of F-box proteins in cancer. Nat Rev Cancer 2014; 14: 233-247.

9 Lau A, Liu Y, Tron A, Inuzuka H, Wei W. The role of FBXW subfamily of F-box proteins in tumorigenesis. SCF and APC E3 ubiquitin ligases in tumorigenesis. SpringerBriefs in Cancer Research. Springer International Publishing: Berlin, Germany, 2014, pp 15-45.

10 Yi YW, Hong W, Kang HJ, Kim HJ, Zhao W, Wang A et al. Inhibition of the PI3K/AKT pathway potentiates cytotoxicity of EGFR kinase inhibitors in triple-negative breast cancer cells. J Cell Mol Med 2013; 17: 648-656.

11 Yi YW, Kang HJ, Kim HJ, Kong Y, Brown ML, Bae I. Targeting mutant p53 by a SIRT1 activator YK-3-237 inhibits the proliferation of triple-negative breast cancer cells. Oncotarget 2013; 4: 984-994.

12 Schneider CA, Rasband WS, Eliceiri KW. NIH Image to ImageJ: 25 years of image analysis. Nat Methods 2012; 9: 671-675.

13 Kang HJ, Hong YB, Kim HJ, Bae I. CR6-interacting factor 1 (CRIF1) regulates NF-E2-related factor 2 (NRF2) protein stability by proteasomemediated degradation. J Biol Chem 2010; 285: 21258-21268.

14 Hou S, Yi YW, Kang HJ, Zhang L, Kim HJ, Kong Y et al. Novel carbazole inhibits phospho-STAT3 through induction of protein-tyrosine phosphatase PTPN6. J Med Chem 2014; 57: 6342-6353.

15 Knight ZA, Gonzalez B, Feldman ME, Zunder ER, Goldenberg DD, Williams $\mathrm{O}$ et al. A pharmacological map of the PI3-K family defines a role for p110alpha in insulin signaling. Cell 2006; 125: 733-747.

16 Yi YW, Kang HJ, Kim HJ, Hwang JS, Wang A, Bae I. Inhibition of constitutively activated phosphoinositide 3-kinase/AKT pathway enhances antitumor activity of chemotherapeutic agents in breast cancer susceptibility gene 1-defective breast cancer cells. Mol Carcinog 2013; 52: 667-675.

17 Sekulic A, Hudson CC, Homme JL, Yin P, Otterness DM, Karnitz LM et al. A direct linkage between the phosphoinositide 3-kinase-AKT signaling pathway and the mammalian target of rapamycin in mitogen-stimulated and transformed cells. Cancer Res 2000; 60: 3504-3513.

18 Cross DA, Alessi DR, Cohen P, Andjelkovich M, Hemmings BA. Inhibition of glycogen synthase kinase-3 by insulin mediated by protein kinase B. Nature 1995; 378: 785-789.

19 Sarbassov DD, Guertin DA, Ali SM, Sabatini DM. Phosphorylation and regulation of Akt/PKB by the rictor-mTOR complex. Science 2005; 307: 1098-1101.

20 Popov N, Schulein C, Jaenicke LA, Eilers M. Ubiquitylation of the amino terminus of Myc by SCF(beta-TrCP) antagonizes SCF(Fbw7)-mediated turnover. Nat Cell Biol 2010; 12: 973-981.

21 Tsai WB, Aiba I, Long Y, Lin HK, Feun L, Savaraj N et al. Activation of Ras/PI3K/ERK pathway induces c-Myc stabilization to upregulate argininosuccinate synthetase, leading to arginine deiminase resistance in melanoma cells. Cancer Res 2012; 72: 2622-2633.

22 Spender LC, Inman GJ. Phosphoinositide 3-kinase/AKT/mTORC1/2 signaling determines sensitivity of Burkitt's lymphoma cells to $\mathrm{BH} 3$ mimetics. Mol Cancer Res 2012; 10: 347-359.

23 Yamamoto A, Tagawa Y, Yoshimori T, Moriyama Y, Masaki R, Tashiro Y. Bafilomycin A1 prevents maturation of autophagic vacuoles by inhibiting fusion between autophagosomes and lysosomes in rat hepatoma cell line, H-4-II-E cells. Cell Struct Funct 1998; 23: 33-42.

24 Marone R, Cmiljanovic V, Giese B, Wymann MP. Targeting phosphoinositide 3-kinase: moving towards therapy. Biochim Biophys Acta 2008; 1784: 159-185

25 Folkes AJ, Ahmadi K, Alderton WK, Alix S, Baker SJ, Box G et al. The identification of 2-(1H-indazol-4-yl)-6-(4-methanesulfonyl-piperazin1-ylmethyl)-4-morpholin-4-yl-t hieno[3,2-d]pyrimidine (GDC-0941) as a potent, selective, orally bioavailable inhibitor of class I PI3 kinase for the treatment of cancer. J Med Chem 2008; 51: 5522-5532.

26 Maira SM, Stauffer F, Brueggen J, Furet P, Schnell C, Fritsch C et al. Identification and characterization of NVP-BEZ235, a new orally available dual phosphatidylinositol 3-kinase/mammalian target of rapamycin inhibitor with potent in vivo antitumor activity. Mol Cancer Ther 2008; 7: 1851-1863.

27 Carnero A. Novel inhibitors of the PI3K family. Expert Opin Investig Drugs 2009; 18: 1265-1277.

28 Yu K, Toral-Barza L, Shi C, Zhang WG, Lucas J, Shor B et al. Biochemical, cellular, and in vivo activity of novel ATP-competitive and selective inhibitors of the mammalian target of rapamycin. Cancer Res 2009; 69: 6232-6240.

29 Hirai H, Sootome H, Nakatsuru Y, Miyama K, Taguchi S, Tsujioka K et al. MK-2206, an allosteric Akt inhibitor, enhances antitumor efficacy by standard chemotherapeutic agents or molecular targeted drugs in vitro and in vivo. Mol Cancer Ther 2010; 9: 1956-1967.

30 Nyfeler B, Bergman P, Triantafellow E, Wilson CJ, Zhu Y, Radetich B et al. Relieving autophagy and $4 \mathrm{EBP} 1$ from rapamycin resistance. $\mathrm{Mol} \mathrm{Ce} / \mathrm{Bio}$ 2011; 31: 2867-2876.

31 Ring DB, Johnson KW, Henriksen EJ, Nuss JM, Goff D, Kinnick TR et al. Selective glycogen synthase kinase 3 inhibitors potentiate insulin activation of glucose transport and utilization in vitro and in vivo. Diabetes 2003; 52 : 588-595.

32 Dalle Pezze P, Sonntag AG, Thien A, Prentzell MT, Godel M, Fischer S et al. A dynamic network model of mTOR signaling reveals TSC-independent mTORC2 regulation. Sci Signal 2012; 5: ra25.

33 Wahane SD, Hellbach N, Prentzell MT, Weise SC, Vezzali R, Kreutz C et al. PI3K-p110-alpha-subtype signalling mediates survival, proliferation and neurogenesis of cortical progenitor cells via activation of mTORC2. J Neurochem 2014; 130: 255-267.

34 Gao D, Inuzuka H, Tseng A, Wei W. Akt finds its new path to regulate cell cycle through modulating Skp2 activity and its destruction by APC/Cdh1. Cell Div 2009; 4: 11.

35 Wei S, Chu PC, Chuang HC, Hung WC, Kulp SK, Chen CS. Targeting the oncogenic E3 ligase Skp2 in prostate and breast cancer cells with a novel energy restriction-mimetic agent. PLOS ONE 2012; 7: e47298.

36 Guardavaccaro D, Kudo Y, Boulaire J, Barchi M, Busino L, Donzelli M et al. Control of meiotic and mitotic progression by the $\mathrm{F}$ box protein beta-Trcp1 in vivo. Dev Cell 2003; 4: 799-812.

37 Margottin-Goguet F, Hsu JY, Loktev A, Hsieh HM, Reimann JD, Jackson PK. Prophase destruction of Emil by the SCF(betaTrCP/Slimb) ubiquitin ligase activates the anaphase promoting complex to allow progression beyond prometaphase. Dev Cell 2003; 4: 813-826.

38 Bashir T, Dorrello NV, Amador V, Guardavaccaro D, Pagano M. Control of the SCF(Skp2-Cks1) ubiquitin ligase by the APC/C(Cdh1) ubiquitin ligase. Nature 2004; 428: 190-193.

39 Wei W, Ayad NG, Wan Y, Zhang GJ, Kirschner MW, Kaelin WG Jr.. Degradation of the SCF component Skp2 in cell-cycle phase G1 by the anaphase-promoting complex. Nature 2004; 428: 194-198.

40 Woo SR, Byun JG, Kim YH, Park ER, Joo HY, Yun $M$ et al. SIRT1 suppresses cellular accumulation of beta-TrCP E3 ligase via protein degradation. Biochem Biophys Res Commun 2013; 441: 831-837.

41 Lee J, Zhou P. Cullins and cancer. Genes Cancer 2010; 1: 690-699.

42 Zhong J, Shaik S, Wan L, Tron AE, Wang Z, Sun L et al. SCF beta-TRCP targets MTSS1 for ubiquitination-mediated destruction to regulate cancer cell proliferation and migration. Oncotarget 2013; 4: 2339-2353. 
43 Duan S, Skaar JR, Kuchay S, Toschi A, Kanarek N, Ben-Neriah Y et al. mTOR generates an auto-amplification loop by triggering the betaTrCP- and CK1alpha-dependent degradation of DEPTOR. Mol Cell 2011; 44: 317-324.

44 Gao D, Inuzuka H, Tan MK, Fukushima H, Locasale JW, Liu P et al. mTOR drives its own activation via SCF(betaTrCP)-dependent degradation of the mTOR inhibitor DEPTOR. Mol Cell 2011; 44: 290-303.

45 Zhao $Y$, Xiong $X$, Sun $Y$. DEPTOR, an mTOR inhibitor, is a physiological substrate of SCF(betaTrCP) E3 ubiquitin ligase and regulates survival and autophagy. Mol Cell 2011; 44: 304-316. (c) (i)

This work is licensed under a Creative Commons Attribution 3.0 Unported License. The images or other third party material in this article are included in the article's Creative Commons license, unless indicated otherwise in the credit line; if the material is not included under the Creative Commons license, users will need to obtain permission from the license holder to reproduce the material. To view a copy of this license, visit http:// creativecommons.org/licenses/by/3.0/ 